\title{
O grupo como fator de inclusão socioafetiva na terceira idade
}

\author{
Alexandra Cardoso da Silva \\ macs.psi@hotmail.com \\ Emiliana Cardoso da Silva \\ m.alex_70@hotmail.com
}

\section{Resumo}

O objetivo deste trabalho é demonstrar que a Dinâmica de Grupos - Grupo de Encontros Rogeriano - é fator de interação social na Terceira Idade, promovendo a integração dos idosos em grupos substitutivos devolvendo-lhes a autoestima e a cidadania. A experiência foi realizada no NETI/UFSC, com vários grupos a partir de 2001. Efetuaram-se 30 encontros com duração de duas horas cada sessão, ministrados por 2 facilitadoras. Como conclusão, constatou-se que existe um processo adaptativo na velhice estimulando a formação dessas mudanças que é multidimensional: na área emocional, facilita a expressão dos sentimentos positivos; na cognitiva estimula aprendizagens relativas ao seu Eu e ao dos Outros; na comportamental há competência pessoal e social.

Palavras-chave: Grupo de encontros. Grupo secundário. Idosos. Integração. Experiência.

\section{The Group as a Socio-affective Insertion Factor in The Third Age}

\begin{abstract}
The objective of this work is to demonstrate that the Group Dynamics - Rogerian Meeting Groups - is an interactional social factor in the Third Age, promoting the interaction of the Third Agers into Substitutive Groups, restoring their self-esteem and citizenship. The experiment was performed at NET/UFSC, with many different groups since 2001 until the present time. Each group had 30 Meetings, lasting for two hours, coordinated by two facilitators.In conclusion it was found that there is an adaptive process in Older Ager that stimulates multidimensional formation changes. In the emotional area, it facilitates the expression of positive feelings; in the cognitive one, it enhances self-knowledge and others awareness and in the behavioral area, stimulates personal and social competences.
\end{abstract}

Keywords: Meeting Groups. Secondary Group. Third Ages. Interaction Experience. 


\section{Introdução}

Demonstrar que o Grupo de Encontros Rogeriano é fator de interação social na Terceira Idade, promovendo a integração dos idosos em grupos substitutivos ou grupos secundários; incluir o idoso na vida comunitária e social por intermédio do Grupo de Encontros; e desenvolver conhecimentos teóricos capazes de fundamentar as observações e intervenções nos grupos de Terceira Idade.

Em 2004, no seu livro “A Revolução dos idosos", Frank Schirrmacher (2005) fez conclusões proféticas e assustadoras a respeito da velhice.

Por que essas conclusões são proféticas e assustadoras? São proféticas porque, segundo seus dados de 1997, o IBGE estima que, em três décadas, o número de pessoas com mais de 80 anos no mundo será quatro vezes maior que sua população atual de idosos. São assustadoras porque o Brasil não está preparado para atender às demandas advindas dessa situação político-social, numa atitude que transcenda os limites pessoais e familiares. Tal conclusão sobre a velhice e a necessidade de integrar as pessoas na sociedade gerou uma série de pesquisas nas universidades. O Núcleo de Estudo da Terceira Idade (NETI) da Universidade Federal de Santa Catarina atua há cerca de trinta anos em pesquisa e ensino de idosos, o que o coloca entre as instituições de nível superior pioneiras no trabalho de grupo com essa faixa etária.

Um dos motivos para realizar o presente trabalho foi a constatação do aumento populacional de Florianópolis nos últimos anos em decorrência da criação de duas universidades, Universidade Federal de Santa Catarina (UFSC) e a Universidade para o Desenvolvimento de Santa Catarina (UDESC), bem como a instalação da sede de organismos federais, como a Eletrosul.

Muitas famílias radicaram-se na Ilha de Santa Catarina em busca de colocação profissional e de um lugar mais seguro para viver, trazendo consigo seus familiares idosos. Outra razão provocadora da pesquisa foi descobrir que muitas pessoas haviam migrado para Florianópolis porque procuravam uma cidade menor e mais tranquila para se estabelecer, uma vez que haviam perdido, por vários motivos, os laços com o seu grupo primário. Perda do cônjuge, saída dos filhos do seu lar, aposentadoria, separações judiciais e doenças limitadoras da autonomia, entre outros problemas, provocaram redução da autoestima, tristeza e estresse nesses idosos.

Quando se efetua a perda do grupo primário surge um sofrimento tão grande que é necessário buscar outro grupo que possa substituí-lo. O poder compartilhar as atividades grupais com pessoas da mesma geração favorece a adaptação do idoso porque facilita o aparecimento de vivências comuns, e a criação de novos laços aumenta seu bem-estar. Uma solução seria criar novas interações, substituindo o grupo primário, enfraquecido ou já inexistente, pelo grupo secundário, no qual novas relações se estabeleceriam.

A metodologia escolhida para essa tarefa foi a Dinâmica dos Grupos com fundamentação rogeriana. O Grupo de Encontro pretende acentuar o desenvolvimento pessoal e aperfeiçoamento da comunicação em relações interpessoais, através de um processo experiencial. Algumas características práticas definem melhor a metodologia de Rogers. Seus grupos são conduzidos por um ou dois facilitadores, que desenvolvem um clima de segurança no qual, com a certeza do sigilo, a liberdade de expressão e a redução de defesa levam a uma aprendizagem grupal. A escolha se baseou no fato de que o grupo é um microcosmo social em que o indivíduo nasce, desenvolve-se e aprende a se relacionar com outras pessoas. Tudo que acontece no microcosmo também acontece no macrocosmo. Sua universalidade e realidade são constantes, pois dele fazem parte até os isolados, esquecidos ou marginalizados. Para Lewin, "O grupo é o solo em que a pessoa se sustenta" (LEWIN, 1973, p. 101).

O grupo é importante para o indivíduo porque é o habitat do ser humano, em que ele vai encontrar: interação, proteção, afetividade, integração e coesão, entre outros sentimentos e mecanismos necessários à sua sobrevivência.

Criado por Carl Rogers, o Grupo de Encontro Rogeriano foi o escolhido para fundamentar a pesquisa porque, entre os demais modelos de laboratórios da Dinâmica dos Grupos, era o que atendia melhor aos propósitos do trabalho por várias razões. A primeira delas foi a sua atualidade como instrumento de pesqui- 
sa e até de terapia. Em sua obra "Psicoterapia de Grupo", Yalon assim se refere a Rogers: "As visões profundas de Carl Rogers do relacionamento terapêutico são tão relevantes hoje em dia quanto foram há quase 50 anos." (YALON, 2006, p. 67); a segunda razão é a flexibilidade com que os grupos podem ser coordenados, respeitando e facilitando o desenvolvimento do processo grupal. O terceiro motivo está mais relacionado aos participantes como sujeitos da pesquisa, pois a metodologia rogeriana, além de facilitar a expressão dos sentimentos e melhorar o autoconhecimento de cada um, possibilita um relacionamento melhor deles entre si, gerando novos laços e interação.

Convém salientar ainda que o papel do coordenador é fundamental no Grupo de Encontro, principalmente nas primeiras sessões. Para Rogers, que preconizava o grupo como uma realidade não estruturada, o facilitador é um criador de ambientes. À medida que o grupo se estrutura e cresce, a importância do facilitador vai diminuindo em favor da coesão grupal. Seu papel diminui à proporção que o grupo se fortalece e se organiza como entidade coletiva. Ele indaga:

'Mas qual a necessidade psicológica que atrai as pessoas para os grupos de encontro?' E expressa sua opinião: 'Creio que seja uma fome de qualquer coisa que a pessoa não encontra no seu ambiente de trabalho, na sua igreja, e com certeza também não na sua escola ou universidade, nem mesmo, infelizmente, na moderna vida de família. É uma fome de relações próximas e verdadeiras, onde sentimentos e emoções se possam manifestar espontaneamente, sem primeiro serem cuidadosamente censurados ou dominados; onde experiências profundas - de decepções e alegrias - se possam mostrar; onde se arrisquem novas formas de comportamento e se levem até ao fim; onde, numa palavra, a pessoa atinja a situação onde tudo é conhecido e aceito, e assim torne possível uma maior evolução. Parece ser esta a fome poderosa que se espera satisfazer através das experiências num grupo de encontro' (ROGERS, 1987, p. 21).

A experiência no NETI foi realizada com vários grupos a partir de 2001. Como a técnica era de laboratório e visava à expansão e ao desenvolvimento de cada pessoa, cada grupo foi limitado a no máximo 20 pessoas. A faixa etária variou de 50 a 87 anos, majoritariamente feminino, na proporção de seis mulheres para cada homem.

No Brasil a legislação estabelece que a Terceira Idade deve se iniciar aos 65 anos. O critério de faixa etária, porém, é duvidoso, uma vez que existem outros critérios que influenciam ou retardam o começo da senescência. Entre esses fatores, estão o estilo de vida, o DNA, a alimentação e doenças. Aceitaram-se, entre os sujeitos da pesquisa, pessoas de 50 anos, pois, além de necessitarem se preparar para a Terceira Idade, poderiam contribuir para a experiências dos demais.

O nível de escolaridade variou da instrução básica à pós-graduação universitária. Esse fato é inédito numa instituição acadêmica, pois ela exige o segundo grau de instrução completo para o ingresso nos seus cursos. Essa aparente liberalidade poderia ser complicadora para que se estabelecesse a coesão grupal, mas não foi o que ocorreu. As diferenças de grau de conhecimento não se tornaram um obstáculo para o relacionamento, uma vez que não se pretendeu transmitir conhecimentos teóricos, mas desenvolver comportamentos e formar atitudes. Os participantes procediam de vários estados da união e até de países vizinhos, como Paraguai, Uruguai e Argentina.

Foram realizados 30 encontros semanais, com a duração de duas horas, todos seguindo os mesmos procedimentos, para que os resultados fossem concluídos dentro de uma única sistemática.

Como o local das atividades era a Universidade Federal de Santa Catarina, alguns participantes da pesquisa esperavam aulas com conteúdo formal ministradas de maneira tradicional. A quebra do paradigma metodológico causou um impacto inicial, assim como a apresentação do contrato psicológico que solicitava a espontaneidade, a disponibilidade e o sigilo no decorrer das sessões. Algumas pessoas demonstraram resistência nas primeiras sessões, outras receberam a nova didática com interesse e boa disposição.

Surgiram algumas indagações: “Onde estão as apostilas?”, "Que livros vamos usar?”, "É preciso fazer anotações?”. 


\section{Análise e Resultados}

No Grupo de Encontro, a expressão dos sentimentos assinala o início das trocas comunicacionais, sendo comuns as hesitações entre o risco de se abrir e a necessidade de confiar no grupo. As primeiras manifestações de sentimentos verdadeiros surgiram, como bem assinalou Rogers, na formalização do sentimento negativo.

"Curiosamente, a primeira expressão de sentimentos significando 'aqui e agora' tem tendência para surgir em atitudes negativas em relação a outros membros do grupo ou ao líder. ” (ROGERS, 1987, p. 29): "Não gosto de gente que vem de 'fora' nos analisar.", "Não dá para falar com outras pessoas falando."

Isso acontece porque é mais fácil expressar os sentimentos negativos do que trazer à tona emoções profundas que são mais perigosas e podem gerar rejeição e respostas agressivas.

$\mathrm{Na}$ prática, com os idosos, percebeu-se que alguns participantes monopolizavam o grupo enquanto outros optavam pelo silêncio. As histórias de vida; a educação rígida sofrida por alguns; o desejo de se incluir ou o medo de fazê-lo nortearam as manifestações iniciais. Na formalização de sentimentos e experiências passadas, surgiam comentários como: "Não gosto de falar sobre o passado.", "O que passou, passou."

Foi preciso mostrar que o passado importava nos encontros, como base para explorar o "Aqui e Agora” e não como uma interpretação do "Lá e Então".

No Grupo de Encontro, a expressão dos sentimentos interpessoais assinala o início das trocas comunicacionais.

É comum a manifestação de afirmações tanto positivas como negativas, como, por exemplo: "Você me lembra o meu pai.", "Não gosto do seu tom de voz quando você fala comigo.", "Aprendi muito com você."

À medida que o grupo evolui, as características pessoais vão aparecendo, os papéis se modificam, as lideranças são substituídas e as duplas se fortalecem. Ao mesmo tempo que as demandas grupais se fortificam, dependendo da disponibilidade do suporte afetivo, os vínculos se estabelecem. Foi assim com os Grupos de Encontro da Terceira Idade.

A passagem de uma fase para a outra é muito peculiar. Cada grupo tem um desenho próprio no seu evoluir, e o ritmo de cada um deles deve ser respeitado. Essas colocações pessoais levam a uma situação de confiança e autenticidade que proporciona a coesão grupal. Enquanto cresce o sentimento solidário, surgem as oportunidades de cada um conhecer melhor a si próprio e aos outros. São comuns as afirmações como: "Somos melhor que o outro grupo." "Isto é próprio deles e não de nós."

Mesmo com o movimento de integração já em curso, ainda podem surgir questionamentos e conflitos. Todavia, a interação continua; pela expressão livre dos indivíduos, uma série de fatos faz com que o participante perceba como os outros o veem. Há um aprendizado em conhecer os próprios defeitos e as próprias qualidades, além de aceitar e lidar com as suas limitações. As afirmações a seguir são exemplo dessa aprendizagem: "Sou uma pessoa muito racional.", "Gosto de mandar nos outros.", "Acho que eu falo demais.", "Por qualquer coisinha eu choro."

Finalmente, na fase seguinte, as pessoas se tornam confiantes e propiciam o surgimento de uma forte coesão, na qual emergem naturalmente as manifestações de afeto e interajuda.

Carl Rogers assim se expressou sobre essa fase de processo grupal:

'Na minha opinião, ficaria incompleta uma descrição do processo de grupo se não mencionasse os vários modos por que os membros se interajudam. Um dos aspectos entusiasmastes de qualquer experiência de grupo é o modo como, quando um indivíduo luta para se exprimir ou se debater com um problema pessoal, ou sofre com uma nova descoberta que fez de si próprio, os membros o auxiliam. Pode acontecer isto dentro do grupo, como já mencionamos, mas ocorre ainda com maior freqüência em contados fora do grupo.' (ROGERS, 1989, p. 41)

Nos grupos de idosos tal resultado é facilmente explicado pelas características semelhantes dos candidatos na sua composição: idade, perda do grupo primário, necessidade de reconhecimento e afeto, desejo 


\section{\begin{tabular}{l|l} 
Extensio & Relato de Experiência
\end{tabular}}

de pertencimento e segurança.

Para se chegar à coesão grupal, foi preciso trabalhar as características individuais que são importantes para o envolvimento das pessoas num resultado comum. Alguns comportamentos podem ser reconhecidos como associativos e outros como dificultadores. Entre os primeiros, podem ser citadas a disponibilidade de participação, a espontaneidade, a tolerância e a amistosidade. Como dificultadores do relacionamento, encontram-se: a agressividade, o isolamento, o autoritarismo e a dificuldade de se expressar emocionalmente.

Cada grupo tem um ritmo e um desenho próprio no seu evoluir. Há de se considerar essa evolução e escolher os exercícios apropriados a cada momento do grupo.

As colocações pessoais levam a uma situação de confiança e autenticidade. O grupo começa a evoluir dentro de um clima de cumplicidade. São comuns afirmações como: "Este é o nosso grupo.", "Somos melhores que o outro grupo", "Isto é próprio deles e não de nós."

Essas verbalizações indicam que foi estabelecida a coesão grupal.

Quando cresce esse sentimento solidário, surge uma mudança nos indivíduos, que passam a se conhecer melhor e se aceitar com suas qualidades e limitações.

Alguns idosos que ocuparam cargos de chefia até a sua aposentadoria chegam deprimidos ou tentam dominar o grupo com iniciativas que são rejeitadas pelos demais; a mãe cujos filhos já se emanciparam e abandonaram a casa paterna busca envolver emocionalmente os participantes, que muitas vezes - ou quase sempre - não aceitam a sedução afetiva.

Ainda assim, a interação continua, e, pela expressão livre dos indivíduos, uma série de fatos faz com que o participante compreenda como os outros o veem.

Está estabelecida a coesão grupal com um estilo e um clima que são exclusivos de cada grupo.

Nos grupos de Terceira Idade, as vitórias e as dificuldades são partilhadas. As manifestações de afeto, tolerância e interajuda são comuns e aparecem numa rede de auxílio mútuo, como: carona no transporte até o local dos encontros; ajuda em caso de doença; solidariedade nas dificuldades pessoais; rede de informações e envio de e-mails com assuntos relativos à Terceira Idade, etc.

Está estabelecida a coesão grupal.

\section{Considerações finais}

Este trabalho teve como objetivo provar que os grupos secundários podem substituir o grupo primário, que se desfez com as perdas sofridas pelos idosos no decorrer de sua existência. Para confirmar essa hipótese, foram formados grupos dentro de laboratórios vivenciais rogerianos - o Grupo de Encontros. Em situação real, os idosos poderiam formar novos laços e estabelecer relações de amizade, reduzindo o estresse e a solidão. Compartilhar atividades grupais com pessoas da mesma geração, possibilitando a emergência de significados comuns, restabelecer a autoestima e promover novos grupos capazes de substituir o grupo primário era a proposta inicial.

Pode-se afirmar que existe um processo adaptativo na velhice, reforçando e estimulando o aparecimento dos grupos substitutivos. O potencial dessas mudanças é multidimensional, pois se efetua nas esferas emocional, cognitiva e comportamental.

Na esfera emocional, se desenvolve a expressão dos sentimentos positivos e negativos, capacitando os participantes da pesquisa a lidarem com as emoções, estabelecerem novos laços afetivos e controlarem os agentes motivadores do estresse. Há até a possibilidade de serem corrigidas situações conflitivas familiares ocorridas no passado, beneficiando-se de uma catarse coletiva favorecida pelo apoio grupal.

$\mathrm{Na}$ esfera cognitiva, há o estímulo para novas aprendizagens relativas ao self e à compreensão do "outro".

Muito inteligentemente, Yalon afirma que: "Não existe um ato ou pensamento humano que esteja completamente fora da experiência das outras pessoas" (YALON, 2006, p. 27), o que autoriza a afirmar que 
o grupo é um extraordinário fator de aprendizagem.

Na esfera comportamental, o indivíduo desperta para o desempenho de atuação pessoal e competência social. A identificação com o outro traz oportunidade de inserção no grupo, enquanto as diferenças levam a um comportamento conciliador e corretivo.

Embora cada qual tivesse um desenvolvimento próprio, a metodologia permanecia a mesma e utilizando os mesmos procedimentos. Os resultados obtidos provaram que é possível substituir o grupo primário pelo secundário quando o primário não existe mais. Pode-se afirmar que existe um processo adaptativo na velhice, estimulando e reforçando os grupos substitutivos.

\section{Referências}

LEWIN, K. Problemas de Dinâmica de Grupo. 2 ed. São Paulo: Cultrix, 1973.

ROGERS, C.R. Grupos de Encontros. 5 ed. São Paulo: Martins Fontes, 1987.

SCHIRRAMACKER, F. A Revolução dos Idosos. Rio de Janeiro: Editora Campos, 2005.

YALOM I. L. M; Psicoterapia de Grupo: teoria e prática. 5 ed. Porto Alegre: Artemed, 2006. 